\title{
The Impact of Cigarette Type on Consumers' Perception of Health Risks of Smoking
}

\author{
Zee Ying Lim, Ai Ling How, Jing Ming Zhao* \\ School of Health Sciences, Ngee Ann Polytechnic, Singapore
}

Copyright (C) 2015 by authors, all rights reserved. Authors agree that this article remains permanently open access under the terms of the Creative Commons Attribution License 4.0 International License

\begin{abstract}
Background: Smoking prevalence in Singapore has increased from $12.6 \%$ in 2006 to $14.3 \%$ in 2011 despite restrictions on tobacco advertising and promotion act, largely due to the strategies of the tobacco industry such as cigarette packaging suggesting lower tar content to target the young and the health conscious. Objectives: To review the perception of health risks of different types of cigarettes across smoking status, age-group and gender, and to determine if smokers perceive differences in health risks based on the taste of cigarettes alone. Method: 240 smokers and 240 non-smokers were presented with cigarette boxes a pair each time and were asked a series of questions on perception of tar content, taste and perceived health risk. Participants who identified themselves as smokers were blindfolded and asked to take 2 puffs of each cigarette type and asked to rate for 'Presence of tar', 'Smoothness of taste' and 'Health risk'. Results: A significant majority of the participants selected 'regular' cigarettes as delivering more tar than 'light' and 'menthol' cigarettes, while 'lights' and 'menthol' cigarettes were perceived as smoother-tasting and being able to reduce health risks. Non-smokers were more susceptible to perceive 'lights' cigarettes as a 'healthier' choice, compared to smokers, but not females or adolescents. Smokers, based on taste alone, rated regular cigarettes to be higher in health risks compared to both 'lights' and 'menthol' cigarettes, which were similarly rated. Discussion: The perception of health risks across different types of cigarettes are affected by the deceptive descriptors on the packaging, but the local increase in prevalence of youth and female smoking cannot be explained by their susceptibility to packaging influences. Taste of cigarettes seems to affect smokers' perception of health-risks as well; hence bans on deceptive descriptors on cigarette packaging may not totally eliminate differences in perception of health risks of different types of cigarettes.
\end{abstract}

Keywords Cigarette Packaging, Health Risk

\section{Introduction}

The prevalence of smoking has decreased since the 1950s to 2007 in the United States, ${ }^{1}$ driven largely by widespread publicity regarding the harmful effects of smoking and restrictions on tobacco advertising and promotion. ${ }^{2}$ Similarly, smoking prevalence in Singapore has decreased from $20 \%$ in 1984 to $12.6 \%$ in 2004 . $^{3}$ However, smoking prevalence in Singapore has increased since then to $14.3 \%{ }^{4}$ This increase deserves our attention, and action needs to be taken in order to reduce the local smoking prevalence.

As the industry recognized consumers' concern for health risks, industry players tried to allay the public's health concern by introducing a 'healthier selection' of cigarettes. They promoted the perception that some cigarettes might be less hazardous, so as to increase their popularity among the currently more well-informed and health-conscious consumers. ${ }^{5}$ In reality, the 'low tar' selections are no less harmful than the higher tar versions, generating low tar and nicotine levels only under machine testing, ${ }^{6}$ but nevertheless delivered much higher levels during consumption. ${ }^{7}$ On consumers' part, however, the perception of health risk has been demonstrated repeatedly to be influenced by cigarette packaging suggesting 'low tar', 'mild', 'smooth'. ${ }^{8-10}$ As explicated in Hammond \& Parkinson, ${ }^{11}$ instead of quitting, some health-conscious smokers have switched to the 'low tar' selection, under the impression that it would minimize their health risks.

When 'lights' cigarettes were compared to regular ones, they were typically believed to be healthier, and this has been demonstrated in the United States ${ }^{12}$ and Canada. ${ }^{11}$ For both of these countries, over $90 \%$ believed 'lights' cigarettes deliver less tar, over $70 \%$ believed they have smoother taste and over $85 \%$ believed they were of lower health risk. In the United Kingdom, where a European Union's directive has banned deceptive descriptors such as 'lights', 'mild', etc. on cigarette packaging since $2003 .{ }^{13}$ In these countries, 'lights' cigarettes were similarly believed to be healthier. However, the extent of being misled by the deceptive descriptors was lower: $69 \%$ believed 'lights' cigarettes delivers less tar, 52\% thought they taste smoother and 57\% thought they were of lower health risk. Furthermore, Zank Smith \& Stutts ${ }^{14}$ found that college students in the United Kingdom were generally aware that 'lights' cigarettes were as harmful as regular ones. These differences in findings suggested that the regulation introduced in the United Kingdom on tobacco packaging has an effect on limiting the extent to which its citizens were 
misled by the deceptive descriptors. While the Food and Drug Administration in United States had only begun prohibiting such descriptors in 2010 , it is likely that its effectiveness would be seen only in the years to come. Currently in Singapore, tobacco companies are still free to use these deceptive descriptors. Given the bulk of research evidence suggesting packaging-related influences on perception of health risks, Singaporeans might likely be found to believe that 'lights' cigarettes were healthier compared to regular ones, at an extent similar to that found in the United States and Canada.

A worrying trend among local young adults is that smoking prevalence among 18-29 year-olds has increased from $12.3 \%$ in 2004 to $17.2 \%$ in $2007 .{ }^{15}$ This may be related to the introduction of flavored cigarettes, as tobacco players identified mildness, smoothness, sweetness and less harsh-tasting cigarettes as being young smokers' preference, $^{16}$ and youths' tendency to perceive non-traditional cigarettes as healthier than traditional ones. ${ }^{17,18}$

Similar to the increase in smoking prevalence among youths, trends in smoking prevalence across genders are note-worthy. Male smoking prevalence has increased from $18.2 \%$ to $25.4 \%$ while female's has increased from $6.6 \%$ to $9.1 \%$. The increase in female smoking prevalence might also be related to the 'slick, sleek, flashy, glittery, shiny, silky, bold' cigarette pack designs targeted at younger women, as women have been admittedly recognized to be tobacco companies' primary target for innovative packaging, as women are particularly involved with the aesthetics of packaging. ${ }^{19}$

Given these trends, our first objective is to determine if youths and females are also more susceptible to perceiving differences in health risks across different types of cigarettes. Similarly, as smokers have been directly exposed to the packaging gimmicks, they might also be more susceptible to such influences. These findings will provide useful information for customizing smoking prevention and intervention programs.

Another objective of this study would be to determine the extent to which smokers taste differed across different types of cigarettes. Studies have demonstrated the 'halo effect' of packaging. ${ }^{20}$ However, these studies typically made comparisons between smoking experience when the packaging was visible and when it was not. Studies have not compared between smoking experiences of different types of cigarettes. Hence, although smokers have often been found to report smoother taste and perceived lower tar delivery in light or mild cigarettes compared to regular ones, ${ }^{11}$ it is unclear if the smoking experiences of different types of cigarettes have influenced their responses, on top of the cigarette packaging. Perceived health risks might also have been modified by taste of cigarettes. Hence, it is of interest to determine if smokers, when administered blind tests, would report differences in perception of taste and health risks between different types of cigarettes.

\section{Methods}

\section{Sample}

Prior to data collection, approval for human participants' involvement was obtained through the Institution Review Board. 240 smokers and 240 non-smokers were recruited between April and June 2011 in Singapore using network non-proportional quota sampling. Both smokers and non-smokers were recruited according to gender and age groups of 18 to 29 years old, 30 to 49 years old, and 50 years old and older. Under each age group, 40 male and 40 female smokers and non-smokers were recruited respectively. Participants were all aged 18 years and above. Because the cigarettes used in the current study was of a brand available in the market, smokers who have tried the brand were excluded from participation.

\section{Cigarette Packs}

Cigarette packs used in this study were NEXT with three different types, namely regular, lights and menthol cigarettes. All of the packs shown to participants displayed the same pictorial health warning covering $50 \%$ of the 'front' of the pack and each type of NEXT has brand descriptors and colour variations.

\section{Data Collection}

After participants were informed of the purpose and duration of the survey, those who provided initial verbal consent were asked to give written consent. After that, participants were asked to be seated at a private area and began by completing a section of the questionnaire on demographics and basic smoking habits and beliefs. Subsequently, participants were presented with cigarette boxes, a pair at a time, and were asked the following three questions: 1) Which packet would you expect to deliver the most tar if you were to smoke it? ; 2) Which packet would you expect to have the smoothest taste?; and 3) If you were to choose between these two types, which one would you buy if you were trying to reduce the risks to your health? They were required to select one of the two packages in response to each question, for a total of 3 pairs of cigarette packages.

Subsequently, only participants who identified themselves as smokers would be asked to complete the next part of the survey. Participants were asked to wear an eye-mask so that they were unable to see the type of cigarette given to them. They were asked to take two puffs of first cigarette. This could be either the regular, lights and menthol cigarettes, which was counter-balanced across participants. Then participants were asked to rate on a scale of 1-7 for 'Presence of tar', 'Smoothness of taste' and 'Health risk'. After that, they were instructed to drink some plain water and rest for 10 minutes, before the second cigarette was presented to them. The same procedure was followed for the second and third cigarette. After the smokers had given their feedback on all three types of cigarettes, they were told to remove their eye-masks. 
Table 1. Level of education of smokers and non-smokers. $\chi^{2}(6)=9.501, p=.147$

\begin{tabular}{|c|c|c|c|c|c|c|c|}
\hline & $\begin{array}{c}\text { No formal } \\
\text { education }\end{array}$ & PSLE & 'O' Levels & 'A' Levels & Diploma & Degree & Post-grad \\
\hline Non-smoker & $19(8.1 \%)$ & $32(13.7 \%)$ & $73(31.2 \%)$ & $18(7.7 \%)$ & $68(29.1 \%)$ & $17(7.3 \%)$ & $7(3.0 \%)$ \\
\hline Smoker & $20(8.5 \%)$ & $47(19.9 \%)$ & $80(33.9 \%)$ & $15(6.4 \%)$ & $44(18.6 \%)$ & $23(9.7 \%)$ & $7(3.0 \%)$ \\
\hline
\end{tabular}

\section{Statistical Analyses}

All analyses were conducted using SPSS software (Version 19.0). Chi-square tests were used to determine participants' perception of whether regular, lights or menthol cigarettes deliver most tar, have the smoothest taste, or could reduce health risk. Binary and multinomial logistic regressions were conducted to determine if gender, age-group and smoking status affected the perceptions of health risks. Repeated measures one-way ANOVA was conducted to compare between participants' ratings of the different types of cigarettes.

\section{Results}

470 participants (239 males and 231 females) who fulfilled the criteria were included in the following analyses. 234 (111 males and 123 females) were non-smokers and 236 (128 males and 108 females) were smokers. Smokers were those who identified themselves as smokers and had smoked at least ten days in the past 30 days. Non-smokers were those who had never smoked any cigarettes. Six respondents considered themselves non-smokers, but reported having smoked at least two days in the past 30 days. Four respondents considered themselves smokers, but reported having smoked less than ten days in the past 30 days. These ten respondents were excluded from further analyses.

\section{Descriptive Statistics}

The mean ages of smokers and non-smokers were 39.28 years $(\mathrm{sd}=15.00)$ and $39.24(\mathrm{sd}=15.54)$ respectively. Table 1 shows their levels of education. Levels of education were verified to be independent of the participants' smoking status , $\chi^{2}(6)=9.501, p=.147$.

A large majority of $80.5 \%$ of the smokers reported smoking for all 30 days in the past 30 days. Overall, the smokers smoked a mean number of $27.5(\mathrm{sd}=5.86)$ days in the past 30 days, and a mean of $9.00(\mathrm{sd}=7.19)$ cigarettes per day.

\section{Perception of Health-risks of Different Types of Cigarettes}

Participants were asked to select between pairs of cigarette boxes presented to them, to determine if they differed in their perception of whether regular, 'lights' or menthol cigarettes deliver most tar, have the smoothest taste, or could reduce health risk (see Table 2).
Table 2. Difference in perception of health risks of different types of cigarettes. Chi-square differences were significant $(p<.001)$ for all comparisons.

\begin{tabular}{|c|c|c|c|}
\hline & $\begin{array}{c}\text { Regular vs } \\
\text { Lights }\end{array}$ & $\begin{array}{c}\text { Regular vs } \\
\text { Menthol }\end{array}$ & $\begin{array}{c}\text { Lights vs } \\
\text { Menthol }\end{array}$ \\
\hline \multirow{2}{*}{ Deliver most tar } & $86.6 \%$ vs & $74.9 \%$ vs & $28.1 \%$ vs \\
& $13.4 \%$ & $25.1 \%$ & $71.9 \%$ \\
\hline Have smoothest & $28.7 \%$ vs & $26.4 \%$ vs & $41.3 \%$ vs \\
taste & $71.3 \%$ & $73.6 \%$ & $58.7 \%$ \\
\hline Reduce health & $15.1 \%$ vs & $24.9 \%$ vs & $71.3 \%$ vs \\
risks & $84.9 \%$ & $75.1 \%$ & $28.7 \%$ \\
\hline
\end{tabular}

Results show that an overwhelming majority selected regular cigarettes as delivering more tar, compared to both 'lights' and menthol cigarettes, while 'lights' and menthol cigarettes were perceived as having smoother taste, and being able to reduce health risks more than regular cigarettes. When the comparison was made between 'lights' and menthol cigarettes, 'lights' cigarettes were perceived as delivering less tar and being able to reduce health risks, though menthol cigarettes were perceived as smoother-tasting.

Logistic regressions were conducted in order to determine if smokers, females and adolescents held different perception of health risks of the different types of cigarettes. The odds ratios for smokers were computed by comparison with non-smokers, while that for females were computed by comparison with males, and adolescents computed by comparison with adults ( 21 years and above). The result of the logistic regression conducted to compare between regular and 'lights' cigarettes is shown in Table 3.

Table 3. Logistic regression results for prediction of selecting 'lights' over regular cigarettes as being able to reduce health risks.

\begin{tabular}{|c|c|c|c|c|c|c|}
\hline & B & S.E. & Wald & df & Sig. & $\begin{array}{c}\text { Odds Ratio } \\
\text { (C.I.) }\end{array}$ \\
\hline $\begin{array}{c}\text { Smoking } \\
\text { status }\end{array}$ & -.670 & .269 & 6.177 & 1 & $.013^{*}$ & $\begin{array}{c}1.953 \\
(1.152-3.312)\end{array}$ \\
\hline Gender & .215 & .262 & .672 & 1 & .412 & $\begin{array}{c}0.807 \\
(0.482-1.348)\end{array}$ \\
\hline Age-gp & .512 & .424 & 1.461 & 1 & .227 & $\begin{array}{c}0.599 \\
(0.261-1.375)\end{array}$ \\
\hline
\end{tabular}

Results show that being a non-smoker is a significant predictor of selecting 'lights' over regular cigarettes as being able to reduce health risks. Specifically, being a non-smoker increases one's odds 1.953 times compared to smokers. Interestingly, although both smokers and non-smokers tend to perceive 'lights' cigarettes as being able to reduce health risks over regular ones, non-smokers were more susceptible to perceive 'lights' cigarettes as a 'healthier' choice. 
Logistic regression conducted for prediction of selection of menthol over regular cigarettes as being able to reduce health risks showed that all three predictors - smoker, gender and age-group, are non-significant, $p>.05$.

The result of the logistic regression conducted to compare between menthol and 'lights' cigarettes is shown in Table 4. Results show that being a smoker is a significant predictor of selecting menthol over 'lights' cigarettes as being able to reduce health risks. Specifically, being a smoker increases one's odds 1.636 times compared to non-smokers.

Table 4. Logistic regression results for prediction of selecting menthol over 'lights' cigarettes as being able to reduce health risks.

\begin{tabular}{|c|c|c|c|c|c|c|}
\hline & $\mathrm{B}$ & S.E. & Wald & $\mathrm{df}$ & Sig. & $\begin{array}{c}\text { Odds Ratio } \\
\text { (C.I.) }\end{array}$ \\
\hline $\begin{array}{c}\text { Smoking } \\
\text { status }\end{array}$ & .492 & .208 & 5.585 & 1 & $.018^{*}$ & $\begin{array}{c}1.636 \\
(1.088-2.461)\end{array}$ \\
\hline Gender & .400 & .207 & 3.739 & 1 & .053 & $\begin{array}{c}1.493 \\
(0.995-2.240)\end{array}$ \\
\hline Age-gp & -.182 & .297 & .377 & 1 & .539 & $\begin{array}{c}0.833 \\
(0.466-1.491)\end{array}$ \\
\hline
\end{tabular}

Comparison of Perceptions of Whether Health Risk is Affected by Taste of Cigarettes

Comparisons were made in perceptions of whether health risk was affected by taste of cigarettes. A significant proportion of the participants wrongly perceived the amount of tar or nicotine in smoother or milder tasting cigarettes to be lower and that stronger or harsher tasting cigarettes were worse for health (see Table 5). A substantial percentage of participants reported that they did not know if taste is related to delivery of tar, nicotine, or health.

Table 5. Difference in perception of health risks as dependent on taste of cigarettes.

\begin{tabular}{|c|c|c|c|}
\hline & No & Yes & $\begin{array}{c}\text { Do not } \\
\text { know }\end{array}$ \\
\hline $\begin{array}{c}\text { smoother/milder tasting cig } \\
\text { deliver less tar }\end{array}$ & $39.36 \%$ & $28.09 \%$ & $32.55 \%$ \\
\hline $\begin{array}{c}\text { smoother/milder tasting cig } \\
\text { deliver less nicotine }\end{array}$ & $43.19 \%$ & $23.40 \%$ & $33.40 \%$ \\
\hline $\begin{array}{c}\text { strong/harsh tasting cig } \\
\text { worse for health }\end{array}$ & $25.11 \%$ & $49.79 \%$ & $25.11 \%$ \\
\hline
\end{tabular}

Multinomial logistic regressions were conducted to determine if smokers, females and adolescents differ in their perception of health risks as dependent on taste of cigarettes. Similarly, the odds ratios for non-smokers were computed by comparison with smokers, while that for males were computed by comparison with females, and adolescents computed by comparison with adults (see Table 6 and 7).

Table 6. Multinomial logistic regression results for predicting if smoother/milder tasting cigarettes deliver less tar.

\begin{tabular}{|c|c|c|c|c|c|c|}
\hline & B & S.E. & Wald & df & Sig. & Odds Ratio (C.I.) \\
\hline "Yes" & \multicolumn{7}{|l|}{} \\
\hline Smoking status & -.202 & .242 & 0.692 & 1 & .405 & $0.817(0.508-1.314)$ \\
\hline Gender & -.546 & .231 & 5.594 & 1 & $.018^{*}$ & $0.579(0.368-0.911)$ \\
\hline Age-gp & .394 & .349 & 1.275 & 1 & .259 & $1.483(0.748-2.940)$ \\
\hline "Don't Know" & \multicolumn{7}{|c|}{} & & & \\
\hline Smoking status & 1.925 & .259 & 55.148 & 1 & $.000^{*}$ & $6.858(4.126-11.400)$ \\
\hline Gender & -.790 & .242 & 10.641 & 1 & $.001^{*}$ & $0.454(0.282-0.729)$ \\
\hline Age-gp & .879 & .337 & 6.789 & 1 & $.009 *$ & $2.408(1.243-4.665)$ \\
\hline
\end{tabular}

Table 7. Multinomial logistic regression results for predicting if smoother/milder tasting cigarettes deliver less nicotine.

\begin{tabular}{|c|c|c|c|c|c|c|}
\hline & B & S.E. & Wald & df & Sig. & Odds Ratio (C.I.) \\
\hline "Yes" & \multicolumn{5}{|l|}{} \\
\hline Smoking status & -.215 & .251 & 0.734 & 1 & .391 & $0.807(0.493-1.319)$ \\
\hline Gender & -.470 & .239 & 3.859 & 1 & $.049^{*}$ & $0.625(0.391-0.999)$ \\
\hline Age-gp & .192 & .366 & 0.276 & 1 & .599 & $1.212(0.591-2.485)$ \\
\hline "Don't Know" & \multicolumn{7}{|c|}{} & & & \\
\hline Smoking status & 1.744 & .246 & 50.123 & 1 & $.000^{*}$ & $5.720(3.529-9.269)$ \\
\hline Gender & -.859 & .235 & 13.404 & 1 & $.000^{*}$ & $0.423(0.267-0.671)$ \\
\hline Age-gp & .880 & .320 & 7.574 & 1 & $.006^{*}$ & $2.412(1.288-4.515)$ \\
\hline
\end{tabular}


Results show that females were more likely to wrongly perceive smoother/milder tasting cigarettes as delivering less tar and nicotine. Females, non-smokers and adolescents were also more likely to indicate they do not know if smoother/milder tasting cigarettes deliver less tar and nicotine.

\section{Blind Test: Smokers' Feedback on Different Types of Cigarettes by Taste Alone}

Smokers were given regular, 'lights' and menthol cigarettes to taste while blind-folded, and asked to provide feedback in terms of the presence of tar, smoothness of taste and health risk on scales of 1 to 7 . The means (and standard deviations) were shown in Table 8.

Table 8. Means and standard deviations of smokers' ratings of different types of cigarette in terms of presence of tar, smoothness of taste and health risk.

\begin{tabular}{|c|c|c|c|}
\hline Cigarette Type & Regular & Lights & Menthol \\
\hline Presence of tar & $5.55(1.62)$ & $3.99(1.74)$ & $4.38(1.64)$ \\
\hline Smoothness of taste & $4.40(1.93)$ & $4.51(1.77)$ & $4.88(1.82)$ \\
\hline Health Risk & $5.48(1.76)$ & $4.31(1.96)$ & $4.53(1.74)$ \\
\hline
\end{tabular}

A repeated measures ANOVA was conducted to compare between the three types of cigarettes in the presence of tar. Results showed a significant difference between the ratings given to the three types of cigarettes, $F(1.911,454.810)=$ $71.775, p<.001$, partial $\eta^{2}=0.232$. Pairwise comparisons showed significant differences between all three types of cigarettes, $p<.001$. Regular cigarettes were rated to be highest in presence of tar, followed by menthol, then 'lights'.

A repeated measures ANOVA was conducted to compare between the three types of cigarettes regarding the smoothness of taste. Results showed a significant difference between the ratings given to the three types of cigarettes, $\mathrm{F}(1.886,450.826)=4.992, p=.007$, partial $\eta^{2}=0.020$. Pairwise comparisons showed significant differences between menthol and the other two types of cigarettes, $p<.01$, but not between regular and 'lights' cigarettes, $p>.05$.

A repeated measures ANOVA was conducted to compare between the three types of cigarettes regarding health risk. Results showed a significant difference between the ratings given to the three types of cigarettes, $F(1.843,440.479)=$ $36.476, p<.001$, partial $\eta^{2}=0.132$. Pairwise comparisons showed significant differences between regular and the other two types of cigarettes, $p<.001$, but not between 'lights' and menthol cigarettes, $p>.05$. Regular was rated as higher in health risk.

From taste alone, smokers rated regular, 'lights' and menthol cigarettes differently. Regular cigarettes were rated to be highest in the presence of tar, while 'lights' the lowest. Smokers found menthol cigarettes have the smoothest taste, but did not find that it differ in health risk compared to 'lights' cigarettes.

\section{Discussion}

\section{Perception of Health Risks of Different Types of Cigarettes}

Consistent with studies conducted in the United States, ${ }^{11}$ participants in this study were more likely to perceive lights and menthol cigarettes as being able to reduce health risks, compared to regular ones. As hypothesized, the percentages of Singaporeans who are being misled are similar to that in United States and Canada. Over $84 \%$ and $74 \%$ considered lights and menthol cigarettes respectively to be delivering less tar than regular ones, and more effective in reducing health risks. It appears that a larger proportion of people from countries where regulations have not or only recently been established against deceptive descriptors tend to be misled by them.

When lights and menthol cigarettes were compared, 71\% perceived lights as delivering lower tar and being able to reduce health risks compared to menthol cigarettes, though menthol cigarettes were perceived as smoother-tasting than lights ones. Moreover, smokers were more likely than non-smokers to perceive menthol cigarettes as being able to reduce health risks compared to lights cigarettes. This may be due to the effect of smokers' experience with the taste of menthol cigarettes.

Contrary to findings in Canada, ${ }^{11}$ the current study found that non-smokers were even more likely than smokers to wrongly perceive lights cigarettes as the healthier choice over regular ones. Hence, though smokers were directly susceptible to packaging gimmicks, and had greater incentive to believe that some cigarettes were healthier than others, they were instead more well-informed than non-smokers regarding the lack of any real health benefits of lights over regular ones. It suggests that Singaporean smokers were relatively more well-informed and had looked into the differences between the choices of cigarettes available to them. This is despite the lack of public education or campaigns of this nature. On the other hand, adolescents and females were not more susceptible to be misled by the deceptive descriptors. Hence, the local increase in prevalence of youth and female smoking cannot be explained by marketing strategies of addressing health concerns used by tobacco companies. Instead, the success of youth-specific and female-specific marketing strategies seems to lie in their attractiveness on the desired image portrayed to youths and females.

\section{Perception of Whether Taste is Related to Health Risks}

The results show that majority wrongly believed that the taste of cigarettes can be used to gauge its tar and nicotine content - that smoother or milder tasting cigarettes do not deliver as much tar and nicotine, while stronger or harsher tasting cigarettes would be worse for health. This finding shows that taste of cigarettes is intricately linked with perception of health risks. As with other foods, whereby taste has been a reliable source of information on health-risks, taste of cigarettes were also thought to be associated with 
health risks, whether by smokers or non-smokers. Perhaps due to the greater reliance and sensitivity of females to tastes, females were found to be more likely to wrongly perceive smoother or milder tasting cigarettes as delivering less tar and nicotine.

Non-smokers, females and adolescents were more likely to indicate that they do not know if taste is related to tar and nicotine content, and health risks, rather than responding with the correct perception that taste is not related to tar and nicotine content. This could be either due to a lack of knowledge of these groups of individuals, or that they were more willing to acknowledge their uncertainty regarding such knowledge.

\section{Perception of Health Risks of Different Types of Cigarettes Based on Taste Alone}

When administered blind tests, smokers were able to differentiate between the regular, lights and menthol cigarettes. This shows that smokers experienced differences between the different types of cigarettes based on taste alone, without product or packaging-related influences. The reported taste differences were in the expected direction, with regular cigarettes rated as higher in health risks compared to menthol and lights cigarettes. It was also found that menthol and lights cigarettes do not differ in their ratings of health risks. Although inconclusive, the data suggests that smokers' ratings of health risks were related to both tar level and smoothness of taste. The lower the rating of tar content in lights cigarettes, compared to menthol, and the smoother taste of menthol cigarettes, compared to lights, both contributed in lowering lights and menthol cigarettes in their ratings of health risks. Hence, both regular and lights cigarettes were rated as similarly lower than regular in terms of health risks. These findings suggests that smokers' perception of the different types of cigarettes were formed not only based on packaging alone, but on the tastes of the cigarettes as well. This may explain why European Union's directive's ban on deceptive descriptors did not completely remove its effect, especially for smokers.

\section{Strengths and Limitations}

Participants were not recruited using random sampling, hence the findings here might not be generalizable to the entire Singaporean population. Nevertheless, the sample here has included a heterogeneous group of smokers and non-smokers of different gender and age-group. Another limitation might be the 'forced choice' nature of types of cigarettes presented for participants' selection. This might result in a higher level of endorsement of the type of cigarettes which might not have been chosen otherwise. Furthermore, there was no option for participants to indicate 'no difference'. However, previous studies which provided this option typically found only less than $5 \%$ of participants selected this option. ${ }^{11}$

\section{Conclusions}

The study confirmed that consumers in Singapore perceive 'lights' and 'menthol' cigarettes as being able to reduce health risk, compared to regular ones. A larger proportion of local consumers perceived such differences in health risks compared to United Kingdom, where regulations against deceptive descriptors have been established for a while. Given the Singapore government's clear policy to curb smoking, it may be helpful to reduce smoking incidence if the health ministry follow the European Union's directive to ban these deceptive descriptors. However, smokers were found to rely on differences in taste to gauge health risks of different types of cigarettes. Hence, the ban on deceptive descriptors on cigarette packaging may not eliminate differences in perception of health risks.

The study also found that local increase in prevalence of smoking among youths and females cannot be explained by tobacco companies' marketing strategies addressing health concerns. Further studies should explore the effects of marketing strategies of tobacco companies in portraying their desired images to youths and females.

\section{REFERENCES}

[1] Infoplease. Smoking Prevalence Among U.S. Adults, 1955-2007. Pearson Education [Internet]. 2010 [cited 2011 September 20], Available from http://www.infoplease.com/ipa/A0762370.html

[2] Wakefield M, Morley C, Horan JK, Cummings KM. The cigarette pack as image: new evidence from tobacco industry documents. Tobacco Control, 2002;11, Suppl 1: i73-i80

[3] Health Promotion Board. Public consultation on proposed amendments to smoking control act. [Internet]. 2007 [cited 2011 September 20], Available from http://www.moh.gov.sg/mohcorp/data/EConsult/756/media $\% 20$ release $\% 20$ public $\% 20$ consultation $\% 20$ final.pdf

[4] Chia HJ. So what? There's no stopping smokers. The Straits Times, 2011, May; pp. 4.

[5] Cummings KM, Morley C, Hyland A. Failed promises of the cigarette industry and its effect on consumer misperceptions about the health risks of smoking. Tobacco Control, 2002; 22, Suppl 1: i110-i116.

[6] US Department of Health and Human Services. Risks associated with smoking cigarettes with low machine measured yields of tar and nicotine. Bethesda, MD: US Department of Health and Human Services, Public Health Services, National Institutes of Health; National Cancer Institute. 2001.

[7] Pollay RW, Dewhirst T. The dark side of marketing seemingly "Light" cigarettes: successful imagees and failed fact. Tobacco Control, 2002; 11, Suppl 1: i18-i31. 
[8] Richter PA, Pederson LL, O’Hegarty MM. Young adult smoker risk perceptions of traditional cigarettes and non-traditional tobacco products. American Journal of Health Behavior, 2006; 30(3): 302-312.

[9] Kropp RY, Halpern-Felsher BL. Adolescents' beliefs about the risks involved in smoking "light" cigarettes. Pediatrics, 2004; 114(4): e445-e451.

[10] Cummings KM, Hyland A, Bansal MA, Giovino GA. What do Marlboro Light smokers know about low tar cigarettes? Nicotine \& Tobacco Research, 2004; 6, Suppl 3: S323-S332.

[11] Hammond D, Parkinson C. The impact of cigarette package design on perceptions of risk. Journal of Public Health, 2009; 31(3): 345-353.

[12] Bansal-Travers M, Hammond D, Smith P, Cummings KM. The impact of cigarette pack design, descriptors, and warning labels on risk perception in the U.S. American Journal of Preventive Medicine, 2011; 40(6): 674-682.

[13] Hammond D, Dockrell M, Arnott D, Lee A, McNeill A.Cigarette pack design and perceptions of risk among UK adults and youth. European Journal of Public Health, 2009; 19(6): 631-637.

[14] Zank GM, Smith KH, Stutts MA. Are light and ultra-light cigarettes safer: perceptions of college students. College
Student Journal, 2008; 42: 1134-1144.

[15] Epidemiology \& Disease Control Division. National Health Surveillance Survey 2007. Singapore: Ministry of Health. 2007.

[16] Wayne GF, Connolly GN. How cigarette design can affect youth initiation into smoking: Camel cigarettes 1983-1993. Tobacco Control, 2002; 11, Suppl 1: i32-i39.

[17] Klein SM, Giovino GA, Barker DC, Tworek C, Cummings $\mathrm{KM}$, O'Connor RJ. Use of flavoured cigarettes among older adolescent and adult smokers: United States, 2004-2005. Nicotine \& Tobacco Research, 2008; 10(7): 1209-1214.

[18] Ashare RL, Hawk LW, Jr Cummings KM, O'Connor RJ, Fix BV, Schmidt WC. Smoking expectancies for flavoured and non-flavoured cigarettes among college students. Addictive Behaviors, 2007; 32 (6): 1252-1261.

[19] Freeman B, Chapman S, Rimmer M. The case for the plain packaging of tobacco products. Addiction, 2008;103:580-590.

[20] British American Tobacco (1978). The vanishing media. Legacy Tobacco Documents Library, [internet]. 1978 [cited 2011 September 20]; Available from http://legacy.library.ucsf.edu/tid/jlf17a99/pdf 